\title{
Radiocarbon Concentration Measurements in Tree Leaves near SOCOCIM (Rufisque, Senegal), A Cement Factory
}

\author{
Maurice Ndeye ${ }^{1}$, Hans-Arno Synal2 ${ }^{2}$, Matar Séne ${ }^{3}$ \\ ${ }^{1}$ Laboratoire Carbone 14, IFAN CH.DIOP, Université Cheikh Anta Diop, Dakar, Sénégal \\ ${ }^{2}$ Laboratory of Ion Beam Physics, ETH, Zurich, Switzerland \\ ${ }^{3}$ Département de physique, Faculté des Sciences et Techniques, Université Cheilkh Anta Diop, Dakar, Sénégal \\ Email: maurice.ndeye@ucad.edu.sn
}

How to cite this paper: Ndeye, M., Synal, H.-A. and Séne, M. (2022) Radiocarbon Concentration Measurements in Tree Leaves near SOCOCIM (Rufisque, Senegal), A Cement Factory. Open Journal of Air Pollution, 11, 1-12.

https://doi.org/10.4236/ojap.2022.111001

Received: December 8, 2021

Accepted: February 8, 2022

Published: February 11, 2022

Copyright $\odot 2022$ by author(s) and Scientific Research Publishing Inc. This work is licensed under the Creative Commons Attribution International License (CC BY 4.0).

http://creativecommons.org/licenses/by/4.0/

\begin{abstract}
Radiocarbon content in biogenic samples is widely used to study the variation of atmospheric $\mathrm{CO}_{2}$ due to anthropogenic activities. A total of 20 samples of several types of tree leaves, were analyzed for this study. Sampling was carried out at the end of the rainy season in 2017 from the surrounding of the SOCOCIM cement factory in Rufisque town. Rufisque is located on the peninsula of Cape Verde, $25 \mathrm{~km}$ east of Dakar, where it is the «south gate» of the agglomeration. Reference samples of five different species were collected during the same period (2017) from a clean zone. The ${ }^{14} \mathrm{C}$ method was used for the determination of $\Delta^{14} \mathrm{C}$ values. The data show that the ${ }^{14} \mathrm{C}$ concentration in the studied sites was significantly lower than the clean area, due to the release of anthropogenic $\mathrm{CO}_{2}$. To estimate the Suess effect, the fossil fuel fraction was determined based on equations of mass balance for $\mathrm{CO}_{2}$ concentration, stable isotopic composition of carbon, and ${ }^{14} \mathrm{C}$ concentration. The results show that selected locations are affected differently according to their distance from the factory and the wind direction.
\end{abstract}

\section{Keywords}

Radiocarbon Concentration, Fossil Fuel Fraction, Tree Leaves, Cement Factory

\section{Introduction}

Radiocarbon $\left({ }^{14} \mathrm{C}\right)$ is produced in the atmosphere by a reaction of neutrons with atmospheric ${ }^{14} \mathrm{~N}$ that produces ${ }^{14} \mathrm{C}$, which is rapidly oxidized into $\mathrm{CO}_{2}$ and then exchanges with different carbon reservoirs. Natural processes such as solar activ- 
ity, Earth's magnetic field, ocean circulation, and rates of exchange between carbon reservoirs all affect the ${ }^{14} \mathrm{C}$ content. Besides these natural variations, human activities also have an impact on atmospheric ${ }^{14} \mathrm{C}$ concentration. Two anthropogenic effects are recorded by atmospheric ${ }^{14} \mathrm{C}$ : first, the Suess effect, which is the addition of carbon dioxide by fossil fuel combustion; and secondly, the increase in ${ }^{14} \mathrm{C}$ concentration in the atmosphere because of atmospheric nuclear weapons testing [1]. Both anthropogenic factors occur on a global scale, however there are also local Suess effects due to local fossil-fuel sources. So, there are regional discrepancies that are related to the emission zone proximity as well as geographic location [2]. If we compare the global ${ }^{14} \mathrm{C}$ atmospheric record to regional or local signals, then it is possible to relate this to regional and local changes in human activities such as industrial activity, traffic, domestic use, and land use. [3] highlighted an example of traffic-derived $\mathrm{CO}_{2}$ in the atmosphere of an urban forest. In this context, the ${ }^{14} \mathrm{C}$ method has been widely used during the last decades, in various applications such as archaeology [4], forensic studies [5], hydrology [6] [7], and geology, and has gained great interest in ecology and environmental studies [8] [9]. During photosynthesis, tree rings, leaves, and short-lived plants assimilate carbon from the air, and provide changes in atmospheric ${ }^{14} \mathrm{C}$ concentration. Due to high dead carbon emissions in industrialized and urban areas, ${ }^{14} \mathrm{C}$ concentrations are diluted [10] [11]. The determination of the ${ }^{14} \mathrm{C}$ content in atmospheric $\mathrm{CO}_{2}$ or from biosphere materials makes it possible to estimate the excess $\mathrm{CO}_{2}$ or the total emission of carbon dioxide of fossil origin [12]. This is based on the differences between radiocarbon concentration in a reference site supposed "clean area" and industrial or urban area. In Senegal we are interested in determining the local variations of ${ }^{14} \mathrm{C}$ concentration due to fossil fuel combustion caused by the different sources of pollution, such as the transport sector, energy stations, and industries. This work aims to calculate the pollution data obtained in the vicinity of a cement factory (SOCOCIM) situated in Rufisque ( $33^{\circ} 37^{\prime} 54^{\prime \prime} \mathrm{N}, 35^{\circ} 26^{\prime} 70^{\prime \prime} \mathrm{E}$ ). In mining, quarrying, crushing, grinding, and calcining generate large amounts of pollutants, mainly $\mathrm{CO}_{2}[13]$. This cement factory located general the cement plant undertakes various processes such as in the town of Rufisque and is created in the 1948's (before independence) however with the expansion of the city the dwellings have moved closer to the site so this could represent a risk to the environment and therefore to the local population. To evaluate this potential pollution a reference site has been chosen in a rural Village of Ngazobil $\left(14^{\circ} 12^{\prime} \mathrm{N}, 16^{\circ} 52^{\prime} \mathrm{W}\right)$ which is far away from the cement factory and should not be affected by the $\mathrm{CO}_{2}$ emissions. Accelerator Mass Spectrometry (AMS) was used to quantify the ${ }^{14} \mathrm{C}$ concentration of the sample material. Measurements have been performed at the ETH Zurich Laboratory of Ion Beam Physics (Switzerland) using a MICADAS instrument. The radiocarbon isotopic ratio $\left(\Delta^{14} \mathrm{C}\right)$ and $\delta^{13} \mathrm{C}$ were determined in 20 samples of several species from tree leaves collected at the two sites. Estimation of the fossil fuel fraction was carried out based on equations of mass balance for $\mathrm{CO}_{2}$ concentra- 
tion, stable isotopic composition of carbon, and ${ }^{14} \mathrm{C}$ concentration [14].

\section{Materials and Methods}

\subsection{Samples}

For this study a total of 20 samples were collected around the cement factory of Rufisque (Figure 1). In the Colobane district, leaves from Azadirachta indica, Albicia le bec and Calotropis procera were collected. Leaves from Prosopis chilensis were collected opposite the factory, $50 \mathrm{~m}$ from the beach. In a salad field in front of the plant, leaves from Prosopis chilensis, peltiferum, Arkin sonia, cordial, Khay, Lecenia were collected. In a distance of only $10 \mathrm{~m}$ from the cement factory samples of Pocéa, aubergine and Goumelia leaves were collected.

These species were chosen because they are widely grown in this region. Thus, the data obtained from this study can be compared to other $\Delta^{14} \mathrm{C}$ determined in different zones in the region. All samples were collected in the same period, at the end of the vegetation season in 2017, to avoid possible seasonal variations of ${ }^{14} \mathrm{C}$ concentration [15]. As reference, leaves from Ngazobil (Figure 1) a site 101.82 $\mathrm{km}$ away from the cement factory located in the municipality of Joal-Fadiouth, in the department of Mbour have been chosen. Five tree leaves samples (Kaya Senegalaisis, Ziziphus mucronata, Albizia, Terminalia catapa, Faderbia albidia) were collected from this clean zone in the same sampling period.

\subsection{Sampling Site}

The climate of the study sites is characterized by the maritime trade winds from the Azores high, from north to north-east, it is constantly humid in winter. The sea trade winds are constantly wet, cool, or even cold in winter. Also, the 'harmattan, of direction East dominant, finishing branch of the continental trade-wind Sahelian, is characterized by a great drought linked to its long continental course, at last the monsoon, comes from the trade-wind resulting from the Anticyclone of Saint Helena in the South Atlantic. It enters the country during the summer in a south-east - north-west direction. It is marked by a low thermal amplitude, but with temperatures generally higher than those of the maritime trade-winds. The rains that fall come from weakened grain lines. They are very weakened. They are very localized in time, usually occur from July to October. However the times when they start and stop are very fluctuating [16] [17].

Samples were collected from rural areas distributed in the vicinity of a cement factory. The selected sites are distinguished by low population density and agricultural land. They are relatively far from large urban cities, about $25 \mathrm{~km}$ from the capital Dakar. The Suess effect could thus be attributed to the potential influence of the cement factory. The first location is situated to the west of the cement factory, while the others are distributed to the north and northeast. Figure 1 presents a map of Senegal showing the location of the studied region and the selected reference zones. Table 1 lists the coordinates of sampling locations, including reference areas, as well as their distance from the factory. 


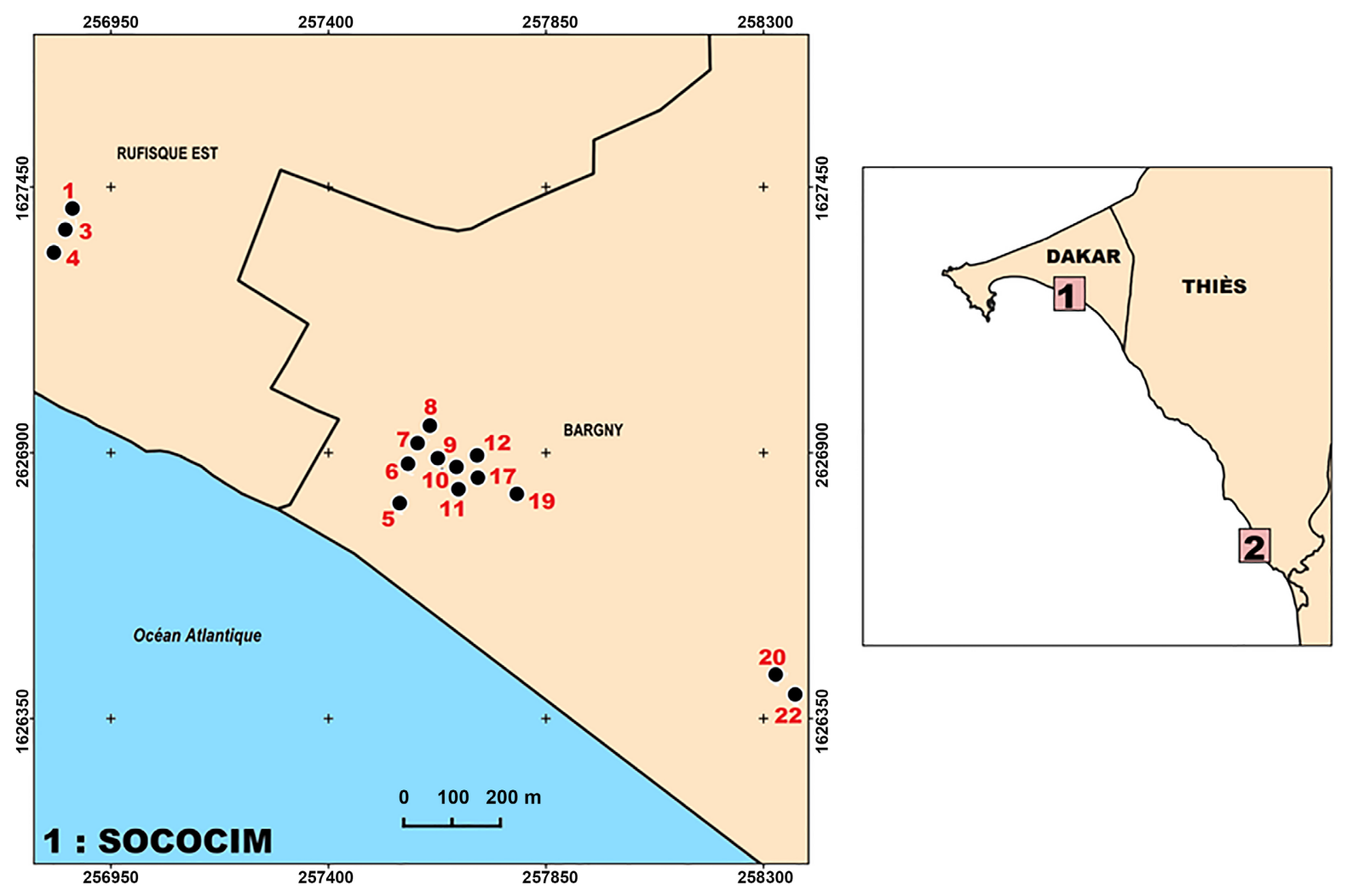

- Collection site Municipality limit

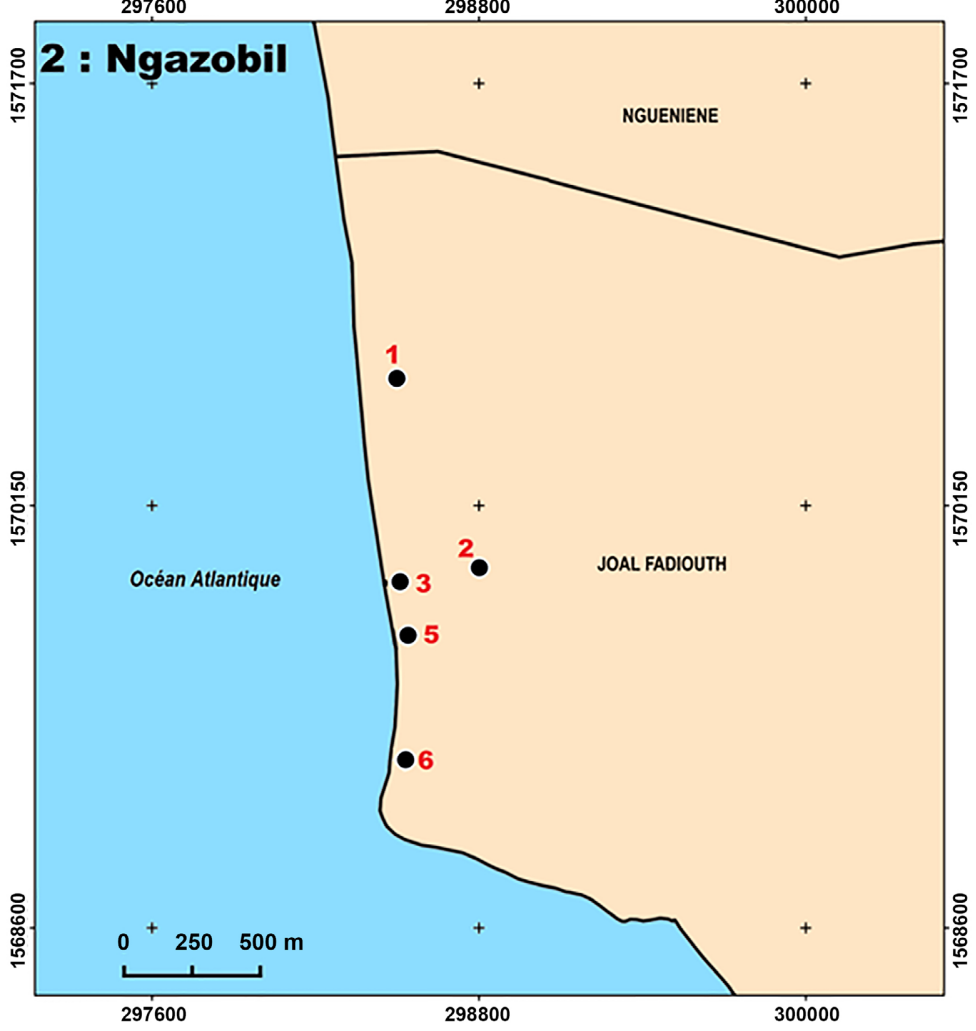

Figure 1. Map of Senegal with the sampling sites indicated (1-sococim, represents the cement plant, 2-Ngazobil is the reference site. The 3rd figure represents the 2 sampling sites in the map of Senegal). 
Table 1. Locations of the sampling site.

\begin{tabular}{|c|c|c|c|c|}
\hline Sample Code & Species/Family & Latitude & Longitude & $\begin{array}{l}\text { Distance from } \\
\text { cement factory }\end{array}$ \\
\hline SOCO01 & Albizia lebbeck/Fabaceae & $\mathrm{N} 14^{\circ} 42^{\prime} 31.8^{\prime \prime}$ & WO $17^{\circ} 15^{\prime} 30.0^{\prime \prime}$ & $60 \mathrm{~m}$ \\
\hline SOCO03 & Moringa oleifera/Moringaceae & $\mathrm{N} 14^{\circ} 42^{\prime} 33.8^{\prime \prime}$ & WO $17^{\circ} 15^{\prime} 29.3^{\prime \prime}$ & $60 \mathrm{~m}$ \\
\hline SOCO04 & Calotropis procera/ Apocynaceae & $\mathrm{N} 14^{\circ} 42^{\prime} 33.8^{\prime \prime}$ & WO $17^{\circ} 15^{\prime} 29.3^{\prime \prime}$ & $60 \mathrm{~m}$ \\
\hline SOCO05 & Prosopis chilensis/Fabaceae & $\mathrm{N} 14^{\circ} 42^{\prime} 16.1^{\prime \prime}$ & WO $17^{\circ} 15^{\prime} 07.9^{\prime \prime}$ & $50 \mathrm{~m}$ \\
\hline SOCO06 & Prosopis chilensis/Fabaceae & $\mathrm{N} 14^{\circ} 42^{\prime} 17.9^{\prime \prime}$ & WO $17^{\circ} 15^{\prime} 05.8^{\prime \prime}$ & $50 \mathrm{~m}$ \\
\hline SOCO07 & Peltophorum africanum/Fabaceae & $\mathrm{N} 14^{\circ} 42^{\prime} 18.3^{\prime \prime}$ & WO $17^{\circ} 15^{\prime} 05.4^{\prime \prime}$ & $50 \mathrm{~m}$ \\
\hline SOCO08 & Parkinsonia aculeata L./Fabaceae & $\mathrm{N} 14^{\circ} 42^{\prime} 18.3^{\prime \prime}$ & WO $17^{\circ} 15^{\prime} 05.4^{\prime \prime}$ & $50 \mathrm{~m}$ \\
\hline SOCO09 & Cordia rothii Roem. \& Schult./Boraginaceae & $\mathrm{N} 14^{\circ} 42^{\prime} 16.1^{\prime \prime}$ & WO $17^{\circ} 15^{\prime} 02.8^{\prime \prime}$ & $30 \mathrm{~m}$ \\
\hline SOCO10 & KHAYA SENEGALENSIS/Meliaceae & $\mathrm{N} 14^{\circ} 42^{\prime} 16.1^{\prime \prime}$ & WO $17^{\circ} 15^{\prime} 02.8^{\prime \prime}$ & $50 \mathrm{~m}$ \\
\hline SOCO11 & Leucaena glauca Benth/Fabaceae & $\mathrm{N} 14^{\circ} 42^{\prime} 16.1^{\prime \prime}$ & WO $17^{\circ} 15^{\prime} 02.8^{\prime \prime}$ & $30 \mathrm{~m}$ \\
\hline SOCO12 & Prosopis chilensis/Fabaceae & $\mathrm{N} 14^{\circ} 42^{\prime} 16.1^{\prime \prime}$ & WO $17^{\circ} 15^{\prime} 02.8^{\prime \prime}$ & $30 \mathrm{~m}$ \\
\hline SOCO17 & poacea/Poacea & $\mathrm{N} 14^{\circ} 42^{\prime} 17.4^{\prime \prime}$ & WO $17^{\circ} 15^{\prime} 00.6^{\prime \prime}$ & $10 \mathrm{~m}$ \\
\hline SOCO19 & Solanum melongena/Solanaceae & $\mathrm{N} 14^{\circ} 42^{\prime} 15.6^{\prime \prime}$ & WO $17^{\circ} 14^{\prime} 58.5^{\prime \prime}$ & $10 \mathrm{~m}$ \\
\hline SOCO 20 & Gmelina arborea/Lamiaceae & $\mathrm{N} 14^{\circ} 42^{\prime} 03.0^{\prime \prime}$ & WO $17^{\circ} 14^{\prime} 39.5^{\prime \prime}$ & $10 \mathrm{~m}$ \\
\hline $\mathrm{SOCO} 22$ & Bougainvillea spectabilis/Nyctaginaceae & $\mathrm{N} 14^{\circ} 42^{\prime} 03.0^{\prime \prime}$ & WO $17^{\circ} 14^{\prime} 39.5^{\prime \prime}$ & $10 \mathrm{~m}$ \\
\hline \multicolumn{5}{|c|}{ Reference sample } \\
\hline Nga01 & Khaya senegalensis/Meliaceae & $\mathrm{N} 14^{\circ} 47^{\prime} 03.0^{\prime \prime}$ & WO $17^{\circ} 02^{\prime} 44.7^{\prime \prime}$ & $101.2 \mathrm{~km}$ \\
\hline $\mathrm{Nga02}$ & Ziziphus mucronata/Rhamnaceae & $\mathrm{N} 14^{\circ} 47^{\prime} 39.9^{\prime \prime}$ & WO $17^{\circ} 02^{\prime} 49.8^{\prime \prime}$ & $101.2 \mathrm{~km}$ \\
\hline $\mathrm{Nga03}$ & Albizia lebbeck/Fabaceae & $\mathrm{N} 14^{\circ} 47^{\prime} 39.9^{\prime \prime}$ & WO $17^{\circ} 02^{\prime} 49.8^{\prime \prime}$ & $101.2 \mathrm{~km}$ \\
\hline Nga05 & Terminalia capata/Combretaceae & $\mathrm{N} 14^{\circ} 47^{\prime} 32.9^{\prime \prime}$ & WO $17^{\circ} 02^{\prime} 49.8^{\prime \prime}$ & $101.2 \mathrm{~km}$ \\
\hline Nga06 & Faidherbia albida/Fabaceae & $\mathrm{N} 14^{\circ} 47^{\prime} 32.9^{\prime \prime}$ & WO $17^{\circ} 02^{\prime} 49.8^{\prime \prime}$ & $101.2 \mathrm{~km}$ \\
\hline
\end{tabular}

\subsection{Chemical Treatment}

Sample material was purified using an acid-base-acid (ABA) protocol. At first the samples were treated with a $0.5 \mathrm{M} \mathrm{HCl}$ solution at $60^{\circ} \mathrm{C}$ for about 2 hours. Following a washing step in deionized water, they were introduced into $0.1 \mathrm{M}$ $\mathrm{NaOH}$ solution at $60^{\circ} \mathrm{C}$ for one hour. After washing again, the materials were introduced into a $0.5 \mathrm{M} \mathrm{HCl}$ solution at $60^{\circ} \mathrm{C}$ for one and a half hour. Finally, the cleaned materials were washed and dried. From the purified materials a subsample containing approximately $1 \mathrm{mg}$ of carbon was taken, packed in an $\mathrm{Al}$ capsule, and introduced into the automated combustion and graphitization system AGE [18], where a catalytic reduction on $4 \mathrm{mg}$ of iron powder of the produced $\mathrm{CO}_{2}$ gas with hydrogen gas took place at $650^{\circ} \mathrm{C}$. Finally, the graphite produced was pressed into $\mathrm{Al}$ cathodes which can be introduced into the ion source of the ETHZ AMS instrument.

\subsection{Measurements and Calculations}

Analysis of samples has been conducted in routine measurements campaigns at 
the LIPMicadas system at the Laboratory of Ion Beam Physics at ETH Zurich (Swiss Federal Institute of Technology) [19].

Two independent measurements were made for each sample, the first on September $5^{\text {th }}, 2021$, and the second on October $13^{\text {th }}, 2021$. For each sample, individual graphite's were prepared using the precleaned material of original sample as described above. The consecutive graphitization of the purified materials enabled preparation of individual cathodes for the AMS analysis. The AMS measurement follows the standard procedure at ETH [20]. SRM 4990C (Oxa II) reference material was used for normalization. Phthalic acid and brown coal samples were used as blank materials. Blank materials were processed in the same way as samples to be analyzed. Thus, eventual contamination during sample preparation can be controlled. During the measurements, the blank materials resulted in less than $0.2 \%$ fraction modern which is equivalent to $50,000 \mathrm{yrs}$ BP. In both measurement runs, final uncertainties of less than $3 \%$ ( $<24 \mathrm{yrs})$ could be reached and the results obtained are nice agreement. By combining both data sets, average values are calculated and final uncertainties of $2 \%$ ( 16 yrs) can be stated.

The conventional radiocarbon age is expressed by the formula above according to [21]:

$$
\operatorname{Age}(B P)=8033 \times \ln \left(\frac{1}{1+\frac{\Delta^{14} \mathrm{C}}{1000}}\right) .
$$

From this equation $\Delta{ }^{14} \mathrm{C}$ values can be deduced

$$
\Delta^{14} \mathrm{C}(\% \mathrm{o})=1000 \times\left(\exp \left(-\frac{\text { Age }}{8033}\right)-1\right)
$$

The $\delta^{13} \mathrm{C}$ values as given in Table 2 are the result of the AMS measurements. They are representative for fractionation effects which may occur during sample preparation and measurement procedure and are used to extrapolate these fractionation effects on the measured $\Delta^{14} \mathrm{C}(\%)$ (calculated from Equation (2)) and are the basis of the applied fractionation correction. They cannot be used to assess the $\delta^{13} \mathrm{C}$ of the original sample material.

\subsection{Estimation of Fossil Fuel Component}

To estimate the local Suess effect in the studied area, the fraction $F(\%)$ of fossil-fuel derived $\mathrm{CO}_{2}$ that was incorporated by the plant material can be calculated according to Equation (3).

$$
F=\frac{\left(\Delta^{14} C_{\text {ref }}-\Delta^{14} C_{\text {meas }}\right)}{\left(\Delta^{14} C_{\text {ref }}-\Delta^{14} C_{\text {foss }}\right)}
$$

A value of $F=10 \%$ indicates that $1 \%$ of the carbon plant material originates from the $\mathrm{CO}_{2}$ emission of the cement factory. We use $\Delta^{14} \mathrm{C}_{\text {foss }}=-1000 \%$, as fossil fuel $\mathrm{CO}_{2}$ is totally depleted of ${ }^{14} \mathrm{C}([22]), \Delta^{14} \mathrm{C}_{\text {ref }}$ is the average radiocarbon content observed at the reference site. 
Table 2. $\delta^{13} \mathrm{C}(\%)$ and $\Delta^{14} \mathrm{C}(\%)$ values for different types of tree leave samples.

\begin{tabular}{|c|c|c|c|c|}
\hline Sample Number & Sample Code & Species/Family & $\delta^{13} \mathrm{C}(\% 0)$ & $\Delta^{14} \mathrm{C}(\%)$ \\
\hline 01 & SOCO1 & Albizia lebbeck/Fabaceae & $-26.85 \pm 0.05$ & $12.0 \pm 2.0$ \\
\hline 03 & $\mathrm{SOCO} 3$ & Moringa oleifera/Moringaceae & $-30.13 \pm 0.05$ & $15.3 \pm 2.0$ \\
\hline 04 & SOCO 4 & Calotropis procera/Apocynaceae & $-29.37 \pm 0.05$ & $11.9 \pm 2.0$ \\
\hline 05 & SOCO5 & Prosopis chilensis/Fabaceae & $-25.18 \pm 0.05$ & $1.6 \pm 2.0$ \\
\hline 06 & SOCO6 & Prosopis chilensis/Fabaceae & $-23.03 \pm 0.05$ & $12.1 \pm 2.0$ \\
\hline 07 & SOCO7 & Peltophorum africanum/Fabaceae & $-20.76 \pm 0.05$ & $13.4 \pm 2.0$ \\
\hline 08 & SOCO 8 & Parkinsonia aculeata L./Fabaceae & $-23.59 \pm 0.05$ & $12.7 \pm 2.0$ \\
\hline 09 & SOCO09 & Cordia rothii Roem. \& Schult./Boraginaceae & $-22.81 \pm 0.05$ & $9.9 \pm 2.0$ \\
\hline 10 & SOCO10 & Khaya Senegalensis/Meliaceae & $-27.24 \pm 0.05$ & $12.5 \pm 2.0$ \\
\hline 11 & SOCO11 & Leucaena glauca Benth/Fabaceae & $-23.98 \pm 0.05$ & $8.9 \pm 2.0$ \\
\hline 12 & SOCO12 & Prosopis chilensis/Fabaceae & $-24.09 \pm 0.05$ & $8.0 \pm 2.0$ \\
\hline 17 & SOCO17 & poacea/Poacea & $-23.76 \pm 0.05$ & $12.6 \pm 2.0$ \\
\hline 19 & SOCO19 & Solanum melongena/Solanaceae & $-27.00 \pm 0.05$ & $12.2 \pm 2.0$ \\
\hline 20 & SOCO 20 & Gmelina arborea/Lamiaceae & $-24.21 \pm 0.05$ & $6,0 \pm 2.0$ \\
\hline 22 & $\mathrm{SOCO} 22$ & Bougainvillea spectabilis/Nyctaginaceae & $-24.39 \pm 0.05$ & $5.0 \pm 2.0$ \\
\hline \multicolumn{5}{|l|}{ Reference Samples } \\
\hline 01 & Nga01 & Khaya senegalensis/Meliaceae & $-26.08 \pm 0.05$ & $15.0 \pm 2.0$ \\
\hline 02 & $\mathrm{Nga02}$ & Ziziphus mucronata/Rhamnaceae & $-26.46 \pm 0.05$ & $16.7 \pm 2.0$ \\
\hline 03 & $\mathrm{Nga03}$ & Albizia lebbeck/Fabaceae & $-23.62 \pm 0.05$ & $14.1 \pm 2.0$ \\
\hline 05 & Nga05 & Terminalia capata/Combretaceae & $-21.79 \pm 0.05$ & $17.9 \pm 2.0$ \\
\hline 06 & Nga06 & Faidherbia albida/Fabaceae & $-25.79 \pm 0.04$ & $15.4 \pm 2.0$ \\
\hline
\end{tabular}

\section{Results and Discussion}

Sampling was done at two sites. The first is the reference site or clean air site

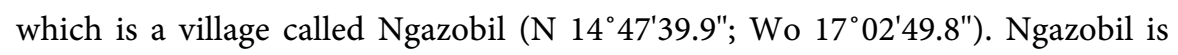
located at the Atlantic Ocean coastline, surrounded by sea waters that often cause winds, and the local air conditions are mostly dominated by seabreeze. The only main activity is fishing, so no industrial complexes and traffic could be responsible for any increase in local fossil $\mathrm{CO}_{2}$ release. Thus, we can regard Ngazobil as free of urban pollution. The $\Delta^{14} \mathrm{C}$ values of the 5 samples (Nga01, Nga03, Nga05, and Nga06) are very consistent and scatter within a $3.8 \%$ range, only. This justifies calculating the average value of $\Delta{ }^{14} \mathrm{C}_{\text {ref }}=15.89 \pm 0.65 \%$ and using it as reference to calculate the $\mathrm{F}$ value of urban pollution at the Rufisque site. It is lower than the value for atmospheric $\Delta{ }^{14} \mathrm{CO}_{2}(51 \%)$ of 2012 as published by [23]. By extrapolating the trend in the Hua data to 2017, a global atmospheric $\Delta^{14} \mathrm{CO}_{2}$ value would result in the range of $\sim 20 \%$. This is still higher than the Ngazobil average value. However, more recent $\Delta^{14} \mathrm{CO}_{2}$ data from Switzerland observed from tree leaves collected between 2012 and 2016, would sug- 
gest a $\Delta{ }^{14} \mathrm{CO}_{2}$ value of $\sim 15 \%$, based on the 2016 result and an average annual decline of $4.4 \%$ (Synal pers. communication). This is in nice agreement with our reference value.

All $\Delta{ }^{14} \mathrm{CO}_{2}$ data at the Rufisque site are lower than the Ngazobil average value (Figure 2). We observe $\Delta^{14} \mathrm{CO}_{2}$ values between $1.6 \%$ and $15.3 \%$. This clearly indicates the impact of the local cement production and the lower the $\Delta^{14} \mathrm{CO}_{2}$ is, the higher is the impact of fossil $\mathrm{CO}_{2}$ releases. In the district of Colobane located $60 \mathrm{~m}$ from the cement factory we observe $\Delta^{14} \mathrm{C}$ values of $11.96 \%, 15.31 \%$, and $11.88 \%$, respectively. Even if these relatively high values remain lower than those obtained at the reference site. The lowest $\Delta^{14} \mathrm{C}(1.57 \%)$ value was observed at a location within a approx. $50 \mathrm{~m}$ range from the leaves of a prosopis chilensis tree. In a salad field at the same distance to the factory, samples SOCO06, SOCO07, SOCO 08 and SOCO10 gave the $\Delta^{14} \mathrm{C}$ values of $12.00 \%$, $13.38 \%$, $12.65 \%$, $9.86 \%$ o and $12.46 \%$ respectively. Although these ${ }^{14} \mathrm{C}$ concentrations are relatively close to the reference value, the impact of the fossil $\mathrm{CO}_{2}$ is significant. On the other hand, four samples (SOCO17, SOCO19, SOCO20 and SOCO22) were taken at a distance of $10 \mathrm{~m}$ from the factory. They fall into two distinct groups, giving values of $\Delta^{14} \mathrm{C} 12.63 \%$, $12.19 \%$ and $5.99 \%$, 5.02\%, respectively. The first group shows a week, the second a rather strong impact from the $\mathrm{CO}_{2}$ emissions. By using Equation (3), these results are converted into fraction fossil fuels $F(\%$.) as shown in Table 3 demonstrating the degree of the Suess effect for each location

\section{$\Delta^{14} \mathrm{C}(\%)$ from tree leaves /Sampling sites}

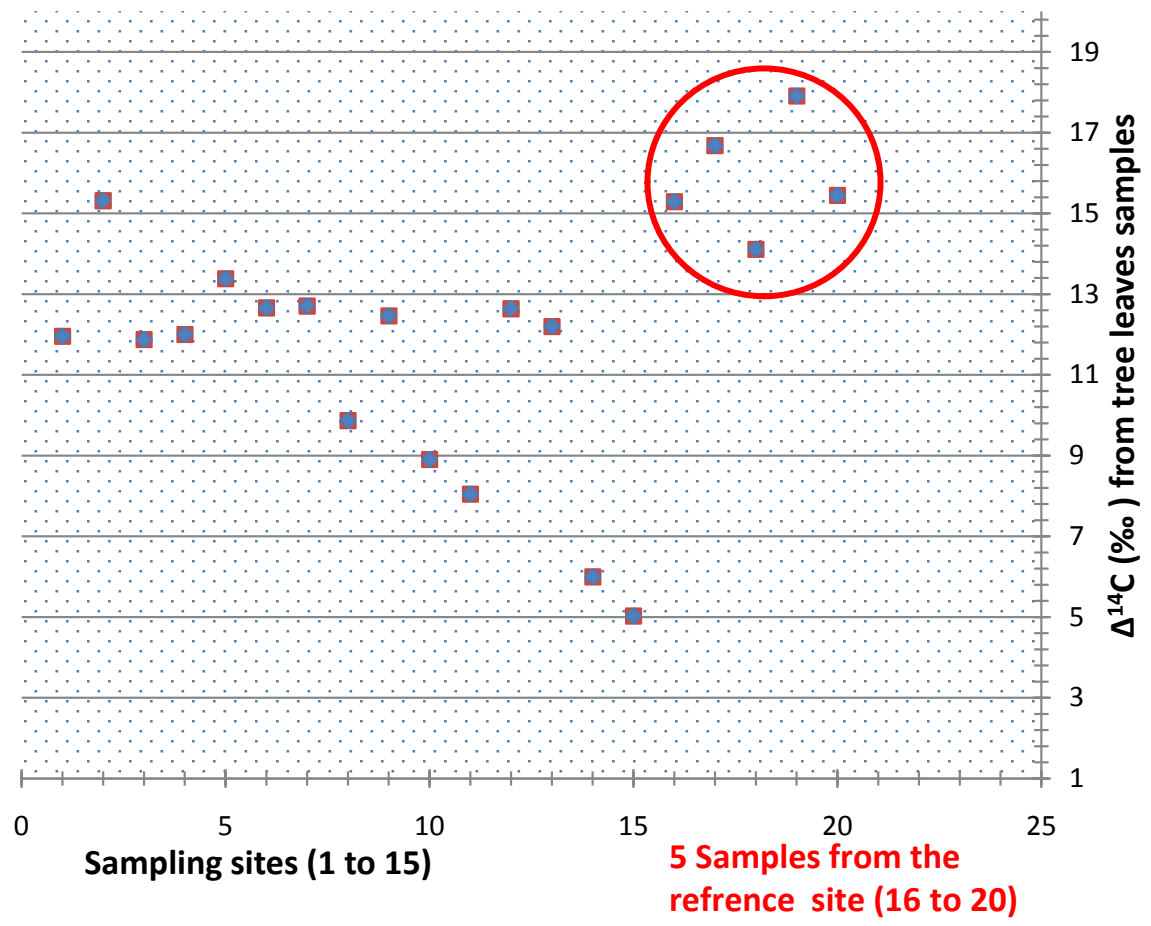

Figure 2. Radiocarbon content $\Delta^{14} \mathrm{C}$ in different types of tree leaves, collected in 2017 from 15 locations of the cement factory compared with 05 samples from the reference area. 
Table 3. Fossil fuel fractions $F(\%)$ in the studied areas derived from ${ }^{14} \mathrm{C}$ content in tree leaves.

\begin{tabular}{ccc}
\hline Sample Code & Species & $F(\%)$ \\
\hline SOCO1 & Albizia lebbeck/Fabaceae & 3.9 \\
SOCO3 & Moringa oleifera/Moringaceae & 0.6 \\
SOCO4 & Calotropis procera/Apocynaceae & 4.0 \\
SOCO5 & Prosopis chilensis/Fabaceae & 14.1 \\
SOCO6 & Prosopis chilensis/Fabaceae & 3.8 \\
SOCO7 & Peltophorum africanum/Fabaceae & 2.5 \\
SOCO8 & Parkinsonia aculeata L./Fabaceae & 3.2 \\
SOCO09 & Cordia rothii Roem. \& Schult./Boraginaceae & 5.9 \\
SOCO10 & KHAYA SENEGALENSIS/Meliaceae & 3.4 \\
SOCO11 & Leucaena glauca Benth/Fabaceae & 6.9 \\
SOCO12 & Prosopis chilensis/Fabaceae & 7.7 \\
SOCO17 & poacea/Poacea & 3.2 \\
SOCO19 & Solanum melongena/Solanaceae & 3.6 \\
SOCO20 & Gmelina arborea/Lamiaceae & 9.7 \\
SOCO22 & Bougainvillea spectabilis/Nyctaginaceae & 10.7 \\
\hline
\end{tabular}

due to anthropogenic ${ }^{14} \mathrm{CO}_{2}$ emissions from the cement factory. In general, there is no clear trend between distance from the factory and the observed ${ }^{14} \mathrm{C}$ depletion a week tendency indicating higher impact at lower distances to the factory may be suggested by the data set. However, very local effect as observed at sampling points SOCO20/22 and SOCO05 may overrule a general tendency. It is remarkable that for these samples between $1 \%-1.5 \%$ of the organic carbon has originated from the fossil fuel emissions of the cement factory.

So far, sampling was carried out on a single season (2017). Confirmation of the values over a longer time period would be helpful to draw more solid conclusions. For an assessment of the Suess effect, these values should be compared with those obtained at points around the alleged source of pollution.

\section{Conclusion}

This study falls within the general framework of the determination of air pollution due to fossil $\mathrm{CO}_{2}$ by the various cement factory installed in Senegal. The SOCOCIM cement factory, which is the oldest in Senegal, was the subject of a collection of samples to determine the excess $\mathrm{CO}_{2}$ due to the anthropogenic effect. A dilution of the ${ }^{14} \mathrm{C}$ concentration was determined following the contribution of the fossil $\mathrm{CO}_{2}$ component emitted by the cement factory. The depletion of ${ }^{14} \mathrm{C}$ in the studied areas can reach an F-value of up to $1.5 \%$ of fossil carbon in the biomass of samples under investigation. This could be attributed to the emissions of cement factory that releases large amounts of $\mathrm{CO}_{2}$, which could 
reach the selected sampling sites with the south-east - north-west direction wind that prevails most of the year. Future studies and measurements will be carried out in the Department of Rufisque to determine the effect of Suess in other nearby villages and observe any change in the atmosphere of the concentration of ${ }^{14} \mathrm{C}$ over time.

\section{Acknowledgements}

The authors express their gratitude to Professor Doudou Diop the researcher in the Botanic Laboratory for his help in the identification (Taxonomy) of the tree leave samples. We thank the laboratory technician Mr. Alpha Diallo for the constant help in taking charge of the collection and pretreatment of samples. Our gratitude goes also strongly to the team of the Laboratory of Ion Beam Physics Zurich (Switzerland) for the constant support to this work.

\section{Conflicts of Interest}

The authors declare no conflicts of interest regarding the publication of this paper.

\section{References}

[1] Ndeye, M., Sène, M., Diop, D. and Salièg, J.F. (2017) Antropogenic $\mathrm{CO}_{2}$ in the Dakar (Senegal) Urban Area Deduced from ${ }^{14} \mathrm{C}$ Concentration in Tree Leaves. Radiocarbon, 59, 1009-1019. https://doi.org/10.1017/RDC.2017.48

[2] Hua, Q. and Barbetti, M. (2004) Review of Tropospheric Bomb ${ }^{14} \mathrm{C}$ Data for Carbon Cycle Modeling and Age Calibration Purposes. Radiocarbon, 46, 1273-1298. https://doi.org/10.1017/S0033822200033142

[3] Takahashi, H.A., Konohira, E., Hiyama, T., Minami, M., Nakamura, T. and Yoshida, N. (2002) Diurnal Variation of $\mathrm{CO}_{2}$ Concentration, $\Delta^{14} \mathrm{C}$ and $\delta^{13} \mathrm{C}$ in an Urban Forest: Estimate of the Anthropogenic and Biogenic $\mathrm{CO}_{2}$ Contributions. Tellus $B$ Chemical and Physical Meteorology, 54, 97-109. https://doi.org/10.3402/tellusb.v54i2.16651

[4] Olsen, J., Heinemeier, J., Hornstrup, K.M., Bennike, P. and Thrane, H. (2013) 'Old Wood' Effect in Radiocarbon Dating of Prehistoric Cremated Bones. Journal of Archaeological Science, 40, 30-34.

[5] Marzaioli, F., Fiumano, V., Capano, M., Passariello, I., De Cesare, N. and Terrasi, F. (2011) Forensic Applications of ${ }^{14} \mathrm{C}$ at CIRCE. Nuclear Instruments and Methods in Physics Research Section B, 269, 3171-3175. https://doi.org/10.1016/j.nimb.2011.04.025

[6] Hoque, M.A. and Burgess, W.G. (2012) ${ }^{14} \mathrm{C}$ Dating of Deep Groundwater in the Bengal Aquifer System, Bangladesh: Implications for Aquifer Anisotropy, Recharge Sources and Sustainability. Journal of Hydrology, 444-445, 209-220. https://doi.org/10.1016/j.jhydrol.2012.04.022

[7] Nakata, K., Kodama, H., Hasegawa, T., Hama, K., Lwatsuki, T. and Miyajima, T. (2013) Groundwater Dating Using Radiocarbon in Fulvic Acid in Groundwater Containing Fluorescein. Journal of Hydrology, 489, 189-200. https://doi.org/10.1016/j.jhydrol.2013.03.012

[8] Battipaglia, G., Marzaioli, F., Lubritto, C., Altieri, S., Strumia, S., Cherubini, P. and 
Cotrufo, M.F. (2010) Traffic Pollution Affects Tree-Ring Width and Isotopic Composition of Pinus pinea. Science of the Total Environment, 408, 586-593. https://doi.org/10.1016/j.scitotenv.2009.09.036

[9] Rakowski, A.Z., Nakamura, T., Pazdur, A. and Meadows, J. (2013) Radiocarbon Concentration in Annual Tree Rings from the Salamanca Region, Western Spain. Radiocarbon, 55, 1533-1540. https://doi.org/10.1017/S0033822200048451

[10] Baydoun, R., Samad, O.E., Nsouli, B. and Younes, G. (2015) Measurement of ${ }^{14} \mathrm{C}$ Content in Leaves near a Cement Factory in Mount Lebanon. Radiocarbon, 57, 153-159. https://doi.org/10.2458/azu rc.57.18108

[11] Muraki, Y., Masua, K., Arslanov, K.A., Toyoizumi, H., Kato, M., Naruse, Y., Murata, T. and Nishiyama, T. (2001) Measurement of Radiocarbon Content in Leaves from Some Japanese Sites. Radiocarbon, 43, 695-701. https://doi.org/10.1017/S0033822200041357

[12] Pataki, D.E., Randerson, J.T., Wang, W., Herzenach, M.K. and Grulke, N.E. (2010) The Carbon Isotope Composition of Plants and Soils as Biomarkers of Pollution. In: West, J.B., Bowen, G.J., Dawson, T.E. and Tu, K.P., Eds., Isoscapes: Understanding Movement, Pattern, and Process on Earth through Isotope Mapping, Springer, Dordrecht, 407-423. https://doi.org/10.1007/978-90-481-3354-3 19

[13] Chabarekh, C. (2010) Air Quality. In: State and Trends of the Lebanese Environment, United Nations Development Program, Lebanon, 101-136.

[14] Levin, I., Kromer, B., Schmidt, M. and Sartorius, H. (2003) A Novel Approach for Independent Budgeting of Fossil Fuel $\mathrm{CO}_{2}$ over Europe by ${ }^{14} \mathrm{CO}_{2}$ Observation. Geophysical Research Letters, 30, Article No. 2194.

[15] Quarta, G., Rizzo, G.A., D’Elia, M. and Calcagnile, L. (2007) Spatial and Temporal Reconstruction of the Dispersion of Anthropogenic Fossil $\mathrm{CO}_{2}$ by ${ }^{14} \mathrm{C}$ AMS Measurements of Plant Material. Nuclear Instruments and Methods in Physics Research Section B, 259, 421-425. https://doi.org/10.1016/j.nimb.2007.02.006

[16] Kama, J. (1996) Travail d'étude et de Recherche. Faculté des Lettres et Sciences Humaines, Département de Géographie, Université Cheikh Anta Diop de Dakar, Dakar.

[17] Diakhaté, A.K. (1994) La problèmatique de l'environnement dans la communauté urbaine de Dakar (Bilan et perspectives des actions menées par les pouvoirs publics et les collectivités locales). Thèse de Doctorat de $3^{\text {em }}$ Cycle Faculté des Lettres et Sciences Humaines, Université Cheikh Anta Diop de Dakar, Dakar.

[18] Wacker, L., Nemec, M. and Bourquin, J. (2010) A Revolutionary Graphitisation System: Fully Automated, Compact and Simple. Nuclear Instruments and Methods in Physics Research Section B, 268, 931-934. https://doi.org/10.1016/j.nimb.2009.10.067

[19] Synal, H.A., Stocker, M. and Suter, M. (2007) MICADAS: A New Compact Radiocarbon AMS System. Nuclear Instruments and Methods in Physics Research Section B, 259, 7-13. https://doi.org/10.1016/j.nimb.2007.01.138

[20] Sookdeo, A., Kromer, B., Büntgen, U., Friedrich, M., Friedrich, R., Helle, G., Pauly, M., Nievergelt, D., Reinig, F., Treydte, K., Synal, H.A. and Wacker, L. (2019) Quality Dating: A Well-Defined Protocol Implemented at ETH for High-Precision 14C Dates Tested on Late Glacial Wood. Radiocarbon, 62, 891-899.

[21] Stuiver, M. and Polach, H.A. (1977) Discussion: Reporting of ${ }^{14} \mathrm{C}$ Data. Radiocarbon, 19, 355-363. https://doi.org/10.1017/S0033822200003672

[22] Pawelczyk, S. and Pazdur, A. (2004) Carbon Isotopic Composition of Tree Rings as 
a Tool for Biomonitoring $\mathrm{CO}_{2}$ Level. Radiocarbon, 46, 701-719. https://doi.org/10.1017/S003382220003575X

[23] Hua, Q., Barbetti, M. and Rakowski, A.Z. (2013) Atmospheric Radiocarbon for the Period 1950-2010. Radiocarbon, 55, 2059-2072. https://doi.org/10.2458/azu js rc.v55i2.16177 